\title{
ANALYSTS' TARGET PRICE ACCURACY AND INVESTORS' REACTION: CHILEAN STOCK MARKET EVIDENCE
}

\section{Jorge Gregoire*}

Facultad de Economía y Negocios, Universidad de Chile

\section{Francisco Marcet}

Facultad de Economía y Negocios, Universidad de Chile

(Received April 19, 2014, accepted June 25, 2014)

\begin{abstract}
The main purpose of this study is to estimate the target price accuracy (TPA) of the Chilean analysts and to find the factors that may affect its accuracy. We also seek to determine if there exists a direct relationship between the precision level of the research divisions and abnormal returns when a new target price (TP) is issued. The empirical results indicate that $26.2 \%$ of TPs (overall) issued were successful. Abnormal returns associated to research divisions with higher accuracy are not observed consistently. Lastly, we find significant abnormal returns when a new TP announced is above (below) to the market consensus.

\section{Resumen}

El principal objetivo de este trabajo es estimar el grado de precisión que tienen los analistas de títulos accionarios en Chile. El estudio busca mostrar evidencia acerca de una directa relación entre el grado de precisión de los analistas y la presencia de retornos anormales en el día del anuncio de un nuevo precio objetivo (PO). Los principales resultados reflejan que los analistas no poseen un grado de precisión elevado, solo el $26.2 \%$ de los POs lanzados al mercado fueron exitosos. Además, se encuentra evidencia de retornos anormales en el día del anuncio de un nuevo PO cuando este sorprende al mercado.
\end{abstract}

JEL Classification: Revisar

Keywords: Target Price Accuracy, Analyst Recommendation, Abnormal Returns

* Universidad de Chile-FEN Diagonal Paraguay 257, Santiago de Chile. Tel: (562) 2978 3358 Email:jgregoir@unegocios.cl fmarcet@unegocios.cl

We are grateful for comments provided by José Luis Ruiz, Ximena García, Arturo Rodriguez, participants of the finance track in CLADEA 2011 and the two anonymous referees 


\section{Introduction}

The Chilean capital market has developed rapidly since the late 90s. The capital market reform and the improvements in macroeconomic stability have fostered the entry of international investors and more domestic agents have started to participate in the Santiago Stock Exchange. Even though IPOs have been somewhat limited in the last decade, the total stock trading volume has increased significantly in recent years.

The increasing entry of investors, the strong penetration of mutual funds and the active role of life insurance and pension funds companies (AFP) in the national market, has led to a professionalization of research departments in brokerage firms and institutional investors. For several years, life insurance companies, pension funds, and brokers have established research divisions to analyze the main firms in the Chilean stock market, especially those in the IPSA stock index (composed of the forty most important companies in Chile) and make stock recommendations based on the public available information.

Research departments have two very important roles inside a brokerage firm. The first one is to do research in order to provide information to their customers (people who invest in securities through the brokerage firm). The second one is to increase the prestige of the company, doing high level research and take advantage in relation to other competitors. Thus, analysts' target prices (TPs) are very important for research departments and through TPs a brokerage firm can expand their prestige and attract more customers.

However, there is no study available in Chile that determines the precision level of analysts concerning target prices (TPs) using a large sample size as we provide in this paper, for this reason is not clear how useful are TPs in Chile and the TPA of the research divisions. Therefore, the main purpose of this study is to estimate the target price accuracy (TPA) of the Chilean analyst and find the factors that may affect its accuracy. We also seek to determine if there is a direct relationship between the precision level of the research divisions in the past and abnormal returns on the day of the announcement. This will shed light on the market's ability to distinguish the quality of research divisions. Finally, due to the power of our data that collect almost the entire TPs launched to the market from 2007 to 2010, we want to find empirical evidence of abnormal returns when a new target price (TP) is greater (or lower when the recommendation associated to the TP is "sell") than all actual TPs.

There is a broad range of literature on the impact of analysts' recommendations on stock returns. Specifically, the effects generated when an analyst change the kind of recommendation for a particular stock (for example, from "hold" to "buy"). However, the empirical evidence for Chile and Latin America is scarce, except the study by Moshirian et al.,(2009), which finds positive or negative abnormal returns if there are positive or negative changes in a firm's prospects, for this reason this work helps to develop new evidence to the performance of the Chilean stock market. Also, TPs are very important in the local stock market, where given the small number of research divisions, the agents are attentive to any brokerage firm, pension funds or life insurance company announcing a new TP in order to update their portfolio if it is necessary. 
We use a novel handed-collected database which contains TPs of all Chilean research departments. Target prices are gathered through direct subscriptions to the reports of other research divisions and access to foreign financial databases. The comparative advantage of that database is that it covers virtually all TPs of Chilean firms. The sample size is a big advantage to this work because the numbers of TPs are large, giving us the possibility to achieve robust results.

The remainder of the paper is organized as follows. Section II reviews prior research. Section III discusses the principal hypotheses. Section IV and $\mathrm{V}$ talk about the data and methodology, respectively. Section VI provides the empirical results. Finally, section VII concludes the paper.

\section{Literature Review}

There is a wide range of literature on the information contribution of the recommendations and TPs, for most international markets. We would like to split the literature review in two streams; the first one is related to the target price accuracy and the second stream is the informational power contents in the target price and stock recommendations. A priori we should expect that analysts with higher target price accuracy would provide more useful information reflecting that on the stock price reactions.

\subsection{Target Price Accuracy}

Bonini et al.,(2010) measure the precision level of TPs for the Italian stocks market. The authors posit that determining the forecast precision or error is important since TPs are a direct measure of the change in the price of the underlying asset. Moreover, a new TP may influence the strategy of an informed investor. The determinants of TPs have also been unexplored and the information held by analysts as specialized agents in a sector and firms in particular provide greater information to the market, thereby affording efficiency when the precision level of the study is relatively high. However, the study finds that the degree of precision is low with high forecast error, and so the question on the efficiency of the market in believing or not this new information agrees with the findings of Jegadeesh and Kim (2006).

Bilinski et al., (2012), using the same variables of Bonini et al.,(2010) find evidence for the target price accuracy in developed markets, they find that analysts exhibit differential and persistent ability to issue accurate TPs and also the accuracy is bigger than the $55.9 \%$.

Bradshaw and Brown (2007) analyze the predictive capacity of analysts and if this capacity varies across different industries. The ability of analysts is important due to the information provided to the market, with which the stock price could vary with the appearance of new TPs. However, according to the efficient markets hypothesis (EMH) of Fama (1970), prices capture all the information available, but agents are expected to determine what information is wrong or obsolete in order to update stock prices. The author presents three forms of EMH, weak, semi-strong and strong. This study focuses on the second, where prices capture all the information from earlier prices plus the publicly available information. In addition, Bradshaw and Brown exploit the implicit expected return of a target price $\left(\frac{T P_{t}}{P_{t}}-1\right)$. Where $T P_{t}$ is the new target price of a company at moment $t$ and $P_{t}$ is the stock price. They find that on average 
the excess implicit expected return with respect to the effective return is $-35 \%$. It finds that only $24 \%$ of analyst forecasts match the forecast price after twelve months (the usual forecast horizon on which to base recommendations and TPs), and that $45 \%$ match the TP within the timeframe. Lastly, the authors do not find a significant difference in TP precision level among analysts.

Bradshaw et. al (2012) using a unique analyst-location data they provide evidence of country-level determinants on the target price accuracy. Countries with better institutional infrastructure in terms of strong protection, transparent financial information and strong cultural forces have a positive effect on analysts' target price accuracy. Markets more transparent and with better financial information permits improve the analyst resources to generate more precise target prices, but also institutional infrastructure permits discipline analysts reducing the incentive to inflate target price. Moreover, Bradshaw (2013) extents the previous study focusing on the analysts' optimism. The author finds that target price optimism is positively associated with proxies for analysts' conflicts of interest, but negatively associated with country-level institutional infrastructure.

\subsection{Information Value of Target Prices}

In this second part we discuss how valuable is the information content in the target prices and stock recommendations. Under the Efficient Market Hypothesis the information content in the stock recommendation and target price is public information, hence the market should not react when an analyst issue a new target price or stock recommendation because they do not provide useful information (all the public information is already reflected on prices). However, several papers provide evidence of stock price reaction when analysts issue a new TP or stock recommendation suggesting that analysts generate informational value with their work, reducing the asymmetric information between outsider and insiders. Moreover, the following literature suggests that TPs and stock recommendation provide useful information to the investors regardless the analysts target price accuracy.

Womack (1996) finds abnormal returns on the day of the event and in subsequent months after a change in recommendation. There is an asymmetry between a recommendation change to a strong sell (from sell) and to a strong buy (from buy). The later has an abnormal return of $2.98 \%$ on average on the announcement day and the former $-1.94 \%$. Jegadeesh and Kim (2006) analyze the recommendations of analysts for the G7 and evaluate the value of those recommendations. They analyze the returns on the announcement day and afterwards and find that the accumulated return increases over time. This finding was common to all the G7 countries except Italy.

Brav and Lehavy (2003) use the hypothesis that TPs provide useful information to the market and they study the possibility of analysts finding abnormal returns on the announcement day. In contrast to Moshirian et al., (2009), the authors carry out the event study with the change in TPs between two successive recommendations. They find that the hypothesis about TP information is correct, the abnormal returns are significantly positive and the information is even useful until six months after the event. There is also a long term relationship between the forecasted price and the actual price, where the former is on average $28 \%$ above the actual price reflecting a long-term 
relationship in the price system.

Feldman et. al (2012) compare how the market response to revisions in target price, stock recommendations and earnings forecast. They attempt to provide evidence of which types of revisions investors consider more informative. In addition, they find that the market response is stronger in a short window periods and the information contents in target price and stock recommendations as compared to earnings forecast revisions is more informative.

On the other hand, Loh and Stulz (2011) argue that no all the stock recommendation revisions have informational value; they posit that only $12 \%$ of stock recommendation revisions influence investors. In addition, only the stock recommendation revisions made by leader, star and influential analysts are taking into account by the market generating an important stock price reaction.

Frankel et. al (2006) provide evidence about the cross sectional determinants of the informativeness of analyst research. The authors suggest that analyst produce more valuable information regarding the firm when the potential brokerage firms are higher and analysts produce less valuable information when the cost associated to the research activities regarding the firm are higher (e.g., analysts spend more resource following a multi-segment firm as compared a firm with only one business line).

Hall and Tacon (2010) argue that analyst studies lead to an increase in market efficiency, due to the reduction in asymmetries of information between company management and external investors participating in the market. This occurs through three new information sources: 1) profits forecasts, 2) analysts' recommendations and 3) TPs.

Even though the predictive capacity of TPs may be lower according to the literature above, new research lines have studied the possibility that together TPs and analysts' recommendations offer complementary information that provides a higher return than could be achieved using the tools separately. Thus, Huang et al.,(2009) finds that the excess return measured through the CAPM, Fama and French and four-factor models is greater in all cases when stock portfolios are created by combining the recommendation and the TP. Finally, Figure 1 shows an overview of the most important papers related with the TP, abnormal returns and international evidence. 
158 Nueva Época REMEF (The Mexican Journal of Economics and Finance)

Figure 1. Literature Review

\begin{tabular}{|c|c|c|}
\hline Topic & Paper & Objective \\
\hline \multirow[t]{4}{*}{$\begin{array}{l}\text { Target Price } \\
\text { Accuracy }\end{array}$} & $\begin{array}{l}\text { Bradshaw and Brown } \\
(2006)\end{array}$ & $\begin{array}{l}\text { They analyze the predictive capacity of analysts } \\
\text { and if this capacity varies across different industries }\end{array}$ \\
\hline & Bonini et al,,(2010) & $\begin{array}{l}\text { They measure the precision level of target prices for } \\
\text { Italian stocks }\end{array}$ \\
\hline & $\begin{array}{l}\text { Bradshaw et. al, } \\
(2012)\end{array}$ & $\begin{array}{l}\text { Using a unique analyst-location data they provide } \\
\text { evidence of country-level determinants on the target } \\
\text { price accuracy }\end{array}$ \\
\hline & Bradshaw (2013) & $\begin{array}{l}\text { Extents the previous study focusing on the analysts' } \\
\text { optimism }\end{array}$ \\
\hline \multirow[t]{2}{*}{$\begin{array}{l}\text { Abnormal } \\
\text { Returns }\end{array}$} & Womack (1996) & $\begin{array}{l}\text { The author finds abnormal returns on the day of the } \\
\text { event and in subsequent months after a change in } \\
\text { recommendation. }\end{array}$ \\
\hline & $\begin{array}{l}\text { Moshirian et } \\
\text { al.,(2009) }\end{array}$ & $\begin{array}{l}\text { They find positive or negative abnormal returns in } \\
\text { emerging markets, if there are positive or negative } \\
\text { changes in analyst's recommendations. }\end{array}$ \\
\hline \multirow{7}{*}{$\begin{array}{l}\text { Informational } \\
\text { Value of target } \\
\text { prices and } \\
\text { analyst } \\
\text { recommendation }\end{array}$} & $\begin{array}{l}\text { Brav and Lehavy } \\
(2003) \text {, } \\
\end{array}$ & $\begin{array}{l}\text { They analyze the short-term reaction and the long- } \\
\text { term behavior of market and target prices. }\end{array}$ \\
\hline & Aquith et al.,(2005) & $\begin{array}{l}\text { They study the level of information provided by the } \\
\text { analyst's recommendation and the market reaction. }\end{array}$ \\
\hline & Huang et al., (2009) & $\begin{array}{l}\text { They find that target price and analyst } \\
\text { recommendation generates higher excess returns if } \\
\text { we use these instruments for investing at the same } \\
\text { time. }\end{array}$ \\
\hline & $\begin{array}{l}\text { Hall and Tacon } \\
(2010)\end{array}$ & $\begin{array}{l}\text { They posit that analyst's research lead to an } \\
\text { increase in market efficiency, due to the reduction } \\
\text { in asymmetries of information between company } \\
\text { management and external investors participating in } \\
\text { the market }\end{array}$ \\
\hline & $\begin{array}{l}\text { Feldman et. al, } \\
\text { (2012) }\end{array}$ & $\begin{array}{l}\text { They compare how the market response to } \\
\text { revisions in target price, stock recommendations } \\
\text { and earnings forecast. }\end{array}$ \\
\hline & Loh and Stuz (2011) & $\begin{array}{l}\text { They argue that no all the stock recommendation } \\
\text { revisions have informational value; they posit that } \\
\text { only } 12 \% \text { of stock recommendation revisions } \\
\text { influence investors. }\end{array}$ \\
\hline & Frankel et. al, (2006) & $\begin{array}{l}\text { They provide evidence about the cross sectional } \\
\text { determinants of the informativeness of analyst } \\
\text { research }\end{array}$ \\
\hline \multirow[t]{2}{*}{$\begin{array}{l}\text { International } \\
\text { Evidence }\end{array}$} & $\begin{array}{l}\text { Jegadeesh and Kim } \\
(2006)\end{array}$ & $\begin{array}{l}\text { They analyze the recommendations of analysts for } \\
\text { the G7 countries and evaluate the value of those } \\
\text { recommendations. }\end{array}$ \\
\hline & Bilinski et al.,(2012) & $\begin{array}{l}\text { Using the same variables of Bonini et al. (2010) } \\
\text { they find evidence for the target accuracy in } \\
\text { developed markets. }\end{array}$ \\
\hline
\end{tabular}

Source: Prepared by authors 


\section{Principal Hypotheses}

Following the line of the literature review and empirical evidence in developed capital markets, our first step is to measure the target price accuracy (TPA) of research departments in the Chilean stock market, and then find the possible determinants of that accuracy, where such as variables are related with the market, volatility of the stock research department fixed effect and research department past performance issuing target prices. Therefore our first hypothesis is the following:

$H_{1}$ : Which variables determinate the accuracy of target prices, controlling by research departments fixed effects?

The first hypothesis is very important to test relationship between the research department's abilities and the investors' reaction to a new target price. We believe that markets react if the new target price provides new and useful information about the stock. But, at the same time investor should react in a different way according to the abilities and prestige of each research department (past performance). For this reason the followings hypothesis try to address the research question whether the market react when a new target price is issued and then whether the investors' reaction differ when the research department have a successful record of target price accuracy.

In addition we use the TP consensus to seek evidence of abnormal returns when a new target is issued. In addition to that, we also would to see if the new TP generates a surprise in the market (according with the TP consensus for a certain stock).

$H_{2}$ : Do we find abnormal returns when a new target price is issued?

$H_{3}$ : Do we find abnormal returns when a new target price issued is above (below) of target price consensus?

The two hypotheses above are related to the market reaction when new information arrives. Finally, we want to test if the market is capable to recognize which brokerage firms are better doing their job and which are the bad ones; for doing that we calculate the abnormal returns when a new TP is issued, controlling for the accuracy that a research department had in the previous year. Therefore our fourth hypothesis is the following:

$H_{4}$ : Are abnormal returns greater when a top ranked research department (in terms of accuracy) issues a new target price?

The last hypothesis is related to the first one in the sense that if investor can identify the main determinant of target accuracy and if one this determinant is the previous research department performance investors should have a higher reaction when the new target price issued is price informative and the issuer has better past performance.

\section{Data}

The database used gathers almost all the TPs in the national market and the research divisions of international investment banks. The initial sample includes 3,467 TPs from the period between March 2005 and November 2010. In addition, the recommendations and TPs are focused primarily on firms that have been part of the IPSA index. The database includes 74 stocks, and 28 research divisions appear in the data. The daily closing prices adjusted for capital variation for those stocks come from Economatica. 
In accordance with Bonini et al.,(2010), we use three criteria to eliminate some stock recommendations that could bias the precision level results: 1) firms that were delisted from the stock exchange 2) firms that merged within the forecast horizon and 3) stocks that only had one TP in their history. The above criteria respond to a lack of ability to observe over time if the precision level changed, and with only one observation we cannot make any inference. Moreover, we eliminate the brokerage firms that only appear with TPs below 4 and stocks with a market presence below $80 \%$ in the estimation period, due to the bias in the market model estimate that can occur with discontinuous trading. This leaves us with 2,969 observations in the precision level estimate. On the other hand 3,163 observations are used to calculate abnormal returns. The difference in sample size arises from the fact that at the moment we were writing the paper, TPs with time horizon December 2011 (that correspond to TPs launched in the second half of the 2010) had not reached to the end of forecast horizon.

\section{Methodology}

\subsection{Target Price Accuracy (TPA)}

This study is based on the variables used by Bradshaw and Brown (2007) and Bonini et al.,(2010). The first step is to measure the precision level or TP error. For this we use four distinct measures that capture the TPA; we will call the first measure POSPT, which has a dummy variable equal to 1 if the stock price at the end of the forecast horizon is greater than or equal to the $\mathrm{TP}$ in the case of a buy recommendation; it is the opposite in the case of a sell recommendation. The second variable is POMPT, which has a value of 1 if the stock at some point in the forecast horizon reached (or exceeded) the TP, and zero if otherwise. The third measure is the difference between the TP minus the closing price at the end of the forecast horizon adjusted by the stock price on the issue date, which we will call POPT. The first two variables are less demanding than the third, since the dummy variable is used to determine if the objective has been achieved, though it does not capture the magnitude of the error like the third. Moreover, when a research division issues the TP of a company, it is automatically providing an "implicit" expected return, defined by $\left(\frac{T P_{t}}{P_{t}}-1\right)$. We can then define a fourth variable (EPO) that measures the error between the implicit return and the actual one with respect to the highest price (lowest price) reached by the stock within the timeframe. We can express this as follows:

$$
\begin{gathered}
\text { if : } \Delta T P_{t}>0 \Rightarrow E P O=\frac{\left|P_{\max }-T P_{t}\right|}{P_{t-3}} \\
\text { if : } \Delta T P_{t}<0 \Rightarrow E P O=-\frac{\left|P_{\min }-T P_{t}\right|}{P_{t-3}}
\end{gathered}
$$

This measure tries to determinate which was the maximum error that the $\mathrm{TP}$ had in the forecast horizon. For this reason we compare the maximum (minimum) price in that interval with respect to TP (conditional to the kind of recommendation).

In the financial industry, research divisions frequently update TPs within the forecast horizon, generally in response to financial reports issued by firms. Therefore TPs need to incorporate this new information when the quarterly 
financial reports stir up the market. Thus, we will use the measures above as follows: when a TP for a firm is issued by a research division, the end of the forecast horizon of the old TP will be taken as three days prior to the announcement. The end of the period is defined as three days earlier because with the next announcement of a new TP, there is a possibility of an overreaction (positive or negative) in the price, and so the results would then be biased. With regard to the forecast horizon, there is a convention in the Chilean financial industry that divides the year into two semesters where the forecast of the first half of the year has an end of forecast time horizon of December of the same year, while forecasts of the second half of the year have an end period of December of the following year. Therefore we label the sample in two parts to determine if the TPA is affected. This avoids the problem of measuring the precision of overlapping periods.

Hence, with the purpose to test the first hypothesis $\left(H_{1}\right)$, the econometric model used is the following:

$$
\begin{aligned}
T P A_{i} & =\alpha+\beta_{i} \cdot \text { Sector variables }+\gamma_{t, 1} \text { Period } \\
& +\gamma_{9} \text { Ranking }_{t-1} * D_{\text {Ranking }_{t-1}} \beta_{10} * D_{\text {Ranking }_{t-1}} \\
& +\beta_{11} \text { Expected } \text { return }_{i}+\beta_{12} \text { Momentum }_{i}+\beta_{13} \text { Sigma }_{i} \\
& +\beta_{14} M R+\beta_{15} \log \left(\text { M Kap }_{i}\right)+\beta_{16} \cdot \text { Buy }_{i}+\beta_{17} \cdot \text { Hold }_{i} \\
& +\delta_{i} \text { ResearchDeparment }+\varepsilon_{i}
\end{aligned}
$$

We will estimate the variables that determinate the TPA using ordinary least squares and a probit model. If the dependent variable (Target Price Accuracy $T P A_{i}$ ) is POPT and EPO we will use OLS, while if it is POST and POMPT we will use a probit model. It is important to note that we will use a least square model for POPT and EPO because these variables are continuous, while we will use a probit model for POST and POMP which are binary variables. If we use a least squares model for a binary variable we will get biased and inconsistent estimators.

The variables that a priori are important in the determination of the TPA are the following: The Sector variable is a group of dummy variables that take the value of one when a stock is part of the following economic sectors used by the Santiago Stock Exchange and Economatica. There are eight such stock indexes: 1) Industry, 2) Banking, 3) Communication and Technology, 4) Retail, 5) Commodities, 6) Construction and Real Estate, 7) Utilities and 8) Consumption. We also add the financial sector that includes the pension fund companies and "Others" sector . A priori we would like to find evidence that the TPA differs from different "sectors". The variable Expected.return $\left(\frac{T P_{t}}{P_{t-3}}-1\right)$ is the upside (or downside) potential of the stock. If the expected return is higher, more demanding is the threshold that determinates if the TP is successful. The stock price three days prior to the announcement is used, because that price should not be affected by the announcement of a new TP. The "Momentum" of the stock price, is measured by the accumulated return of the stock within the forecast horizon, "Sigma" is the volatility of the stock within the forecast horizon. " $M R$ " is the IPSA return in the forecast period. If the volatility of the stock, market return and momentum are higher, the probability of reaching 
the TP is higher. The market capitalization of a firm, measured in natural logarithm "Ln(MKCap)" captures any specific effect of the firm and serves to control for omitted relevant variables, measured at the TP issuance date. "Ranking $t_{t-1}$ ", is the precision level of the research divisions for the previous period, ranked from greater to lower level of precision and grouped by quintiles, if the research department had a good performance, the TPA would be higher in the future. "D Rankingt-1 $_{t-1}$ is a dummy variable with the value of 1 if the firm had TPs in the previous year. A probit model is used to estimate the coefficient, since both POST and POMPT are dummy variables that take the value of one or zero. For the other two measurement techniques we will use ordinary least squares corrected for heterocedasticity and autocorrelation. In addition, "Research Department" are dummies that represent which brokerage firm issued a new TP. The Hold and Buy variables are dummies with the value of 1 if the recommendation is buy or hold and zero if otherwise (the sell Dummy is captured in the constant, since if we included it in the regression there would be a linearly dependent variable and the information matrix could not be inverted). Finally, "First Semester" or "Second Semester" are dummy variables for TPs issued in the first and second semester of each year, respectively. A priori we would like see if the time is a determinant of the TPA.

\subsection{Event Studies and Abnormal Returns.}

With the purpose to determine if a new TP produces abnormal returns $\left(H_{2}\right)$, we must define an event window from one day prior to one day after the event. In addition, we can define three stages: 1) estimate window, where the parameters of the market model are calculated as well as the constant mean of the asset's return in order to compare it with the actual return; 2) event window, which is the time period of the TP announcement, and where a window of three days is used to avoid overlapping events that can bias the results of a particular event.

Since the TPA of brokerage firms has been calculated, we can verify if exists abnormal returns in the announcement window when the market reacts based on the reputation of research divisions $\left(H_{3}\right)$, measured by the Ranking $g_{(t-1)}$ variable or if a new TP delivers new information to the stock market. Finally, we will use the same methodology for testing if there are abnormal returns when a new TP is announced above (below or equal) to the market consensus $\left(H_{4}\right)$. According to Mackinlay (1997) the market model is useful to determine abnormal returns:

$$
R_{i t}=\alpha_{i}+\beta_{i} R_{m \tau}+\epsilon_{i \tau}
$$

We used a sample of 200 daily data and $T_{0}$ y $T_{1}$ is the beginning and end of the estimation period. Thus, the estimated return (theoretical) of the stock $i$ at $t$ is:

$$
\hat{R}_{i t}=\hat{\alpha}_{i}+\hat{\beta}_{i} R_{m \tau}
$$

After obtaining the parameters of the market model and calculate $\hat{R}_{i t}$, we can define the abnormal return or error term in the event period:

$$
\widehat{A R}_{i \tau}=R_{i t}-\hat{R}_{i \tau}
$$


Abnormal return (error term $\left.\epsilon_{i \tau}\right)$ is distributed $N \sim\left(0, \sigma_{\left(\widehat{A R}_{i \tau}\right)}^{2}\right)$. The variance is defined as follow:

$$
\sigma_{\left(\widehat{A R}_{i \tau}\right)}^{2}=\sigma_{\epsilon_{i}}^{2}+\frac{1}{T_{1}-T_{o}} \frac{\left[1+\left(R_{m \tau}-\hat{\mu}_{m}\right)^{2}\right]}{\hat{\sigma}_{m}^{2}}
$$

The first term is the variance of the market model error in the estimation period and the second component is a product of sampling error correction due to the event period. At this moment we have characterized the abnormal return at the exact time when the event occurred. However, it is necessary to aggregate the return of one day prior and one day after the event as a result of capturing the possible leak of information about the event and a possible slow market reaction to new information. Therefore, the aggregate abnormal returns of the event period are:

$$
\widehat{C A R} R_{\left[\tau_{1}, \tau_{2}\right]}=\sum_{t=\tau_{1}}^{\tau_{2}} \widehat{A R}_{i \tau}
$$

Thus, the sum of the abnormal returns within the event period starts one day before and finish one day after of the event $\left[\tau_{1}, \tau_{2}\right]$. Moreover, the variance (asymptotically) in the event period is defined as:

$$
\sigma_{\left[\tau_{1}, \tau_{2}\right]}^{2}=\left(\tau_{2}-\tau_{1}+1\right) \sigma_{\epsilon}^{2}
$$

The aggregate returns are distributed $\widehat{C A R} \sim N\left(0, \sigma_{\left[\tau_{1}, \tau_{2}\right]}^{2}\right)$ and the null hypothesis is that in the event period abnormal returns aggregates are distributed with mean zero. Now we can add the abnormal returns for different events:

$$
\overline{A R}_{\tau}=\frac{1}{N} \sum_{i=1}^{N} \widehat{A R}_{i \tau}
$$

Where $N$ is the size of the event sample, and $\tau$ is a certain day within event period. The above equation calculates the average excess return on event day $\tau$. After calculating the average abnormal return for each day of the event period $\left[\tau_{1}, \tau_{2}\right]$, now it is necessary to calculate the average aggregate return of event period. Thus, $\overline{C A R}_{\left[\tau_{1}, \tau_{2}\right]}$ is defined as:

$$
\overline{C A R}_{\left[\tau_{1}, \tau_{2}\right]}=\sum_{\tau=\tau_{1}}^{\tau_{2}} \overline{A R}_{\tau}
$$

And the variance of $\overline{C A R}_{\left[\tau_{1}, \tau_{2}\right]}$ is:

$$
\operatorname{Var}\left(\overline{C A R}_{\left[\tau_{1}, \tau_{2}\right]}\right)=\sum_{\tau=\tau_{1}}^{\tau_{2}} \operatorname{Var}\left(\overline{A R}_{\tau}\right)=\frac{1}{N^{2}} \sum_{i=1}^{N} \sigma_{i_{\left[\tau_{1}, \tau_{2}\right]}^{2}}^{2}
$$


Therefore, $\overline{C A R}_{\left[\tau_{1}, \tau_{2}\right]}$ (follows a distribution $\sim N\left(0, \operatorname{Var}\left(\overline{C A R}_{\left[\tau_{1}, \tau_{2}\right]}\right)\right)$. And the null hypothesis of no abnormal excess returns follows a normal standard distribution $\sim N(0,1)$. Thus, the statistic is defined asymptotically as:

$$
\frac{\overline{C A R}_{\left[\tau_{1}, \tau_{2}\right]}}{\sqrt{\operatorname{Var}\left(\overline{C A R}_{\left[\tau_{1}, \tau_{2}\right]}\right)}} \sim N(0,1)
$$

\section{Results}

\subsection{Precision level}

According to the precision level measured by the POST variables, Table 1 shows that $26.2 \%$ of the entire TPs were successful (higher or lower depending on the kind of recommendations) at the end of the forecast horizon (See table 1A). By kind of recommendation, the precision level in the case of sales is $21.1 \%$, while for hold and buy it is $39.4 \%$ and $20.2 \%$ respectively for the entire sample. Over time, the precision level of TPs has increased, especially in the case of hold and buy. However, in most years the precision level has not reached $50 \%$. By brokerage firms, ${ }^{1}$ there is no characteristic pattern defining a higher ability for forecasting TPs. Meanwhile, in not reported tables we find evidence that the greater number of TPs issued by brokerage firms does not ensure a higher precision level. In relation to different sectors for POST variable (See Table 1B), retail (35.6\%) and construction (37.5\%) perform better in TPs, while the financial sector performs worst. ${ }^{2}$ The hold recommendation in the retail sector exhibits the highest precision level with $54 \%$ of TPs hitting their mark. Finally, the years 2009 and 2010 show the higher performance of the TPs.

The results of the POMPT variable (see Table 1B) are in the same line with the above results. However, there is an increase in precision level, which is consistent with the kind of measure. This measure is less demanding than POST, since by expecting that the TP is reached within the forecast horizon it provides greater freedom in the result. The precision levels for the sell, hold, and buy recommendations are $31.3 \%, 53.3 \%$ and $27.2 \%$ respectively. The best performance was in 2009 where the TPA was higher than $50 \%$ for each kind of recommendation.

Regarding the POPT variable the sell recommendation has an average error of $-11.3 \%$, while for the hold and buy recommendations it is $1.6 \%$ and $22.4 \%$ respectively. Finally, the EPO variable reflects an average prediction error of $14.6 \%$, with the buy recommendation having the lowest prediction error.

\footnotetext{
1 We do not report the tables for the industry and research division. However, the results are consistent with table 1 .

2 The results by sector for the POMPT, POPT and EPO measures are not reported. However, the same conclusions are reached as for the POST variable.
} 
Table 1A: Target Price Accuracy by Year

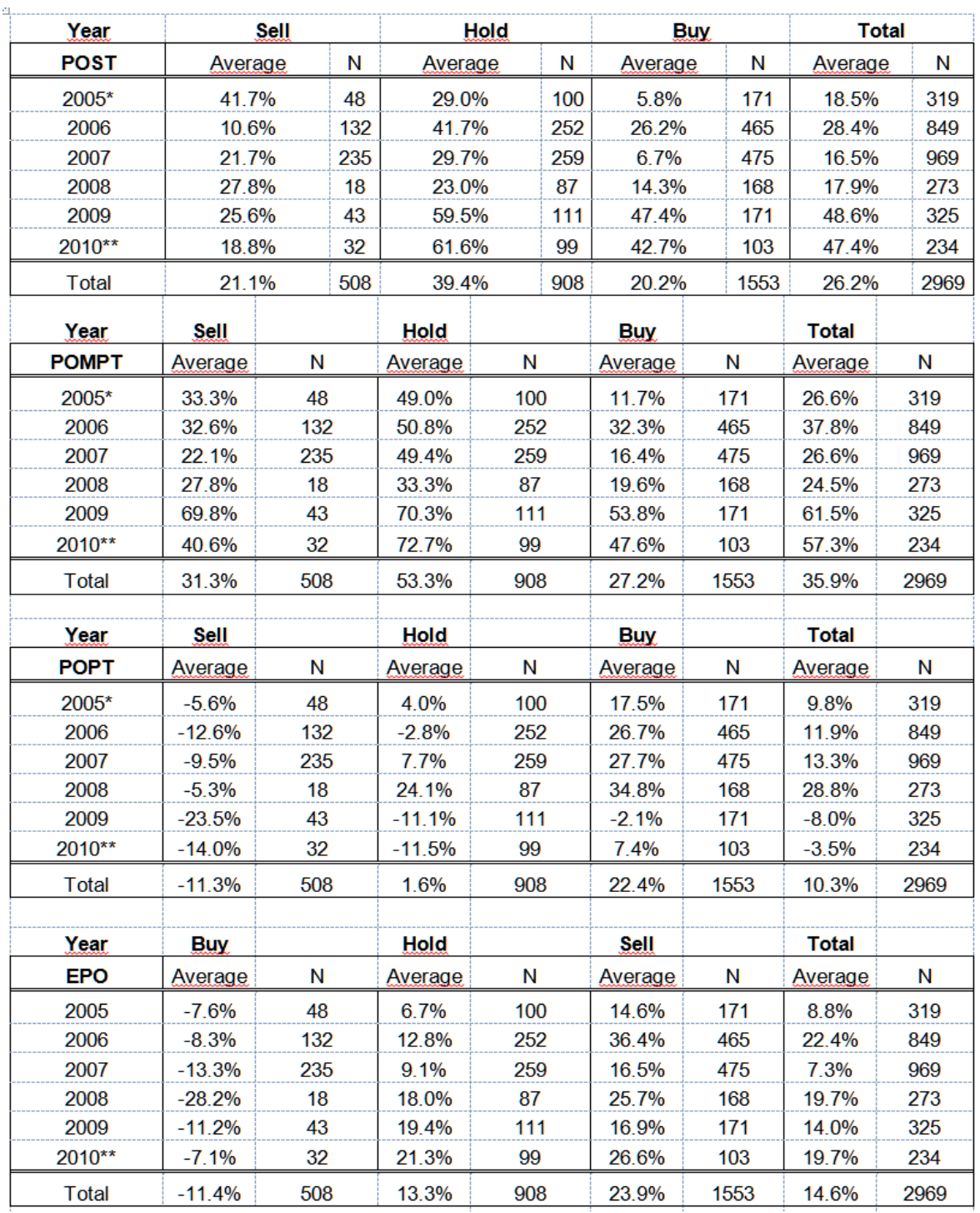

*Observations start in March 2005. **There are observations until June 2010

Source: Prepared by authors 
Table 1B: Target Price Accuracy for POST variable (March 2005- June 2010)

\begin{tabular}{|l|c|c|c|c|c|c|c|c|}
\hline Sector & \multicolumn{2}{|c}{ Sell } & \multicolumn{2}{c|}{ Hold } & \multicolumn{2}{c|}{ Buy } & \multicolumn{2}{c|}{ Total } \\
\hline \multicolumn{1}{|c|}{ POST } & Averaqe & $\mathrm{N}$ & Averaqe & $\mathrm{N}$ & Averaqe & $\mathrm{N}$ & Averaqe & $\mathrm{N}$ \\
\hline \hline Industry & $37.5 \%$ & 24 & $35.5 \%$ & 76 & $15.0 \%$ & 260 & $20.8 \%$ & 360 \\
\hline Utilities & $21.7 \%$ & 83 & $27.7 \%$ & 191 & $14.4 \%$ & 312 & $19.8 \%$ & 586 \\
\hline Other & $0.0 \%$ & 5 & $33.3 \%$ & 3 & $0.0 \%$ & 4 & $8.3 \%$ & 12 \\
\hline Com \& Tec & $34.8 \%$ & 23 & $25.3 \%$ & 83 & $19.3 \%$ & 140 & $22.8 \%$ & 246 \\
\hline Consumption & $28.4 \%$ & 67 & $36.7 \%$ & 120 & $16.8 \%$ & 173 & $25.6 \%$ & 360 \\
\hline Commodities & $12.6 \%$ & 159 & $53.6 \%$ & 168 & $26.7 \%$ & 191 & $31.1 \%$ & 518 \\
\hline Banking & $23.3 \%$ & 60 & $37.9 \%$ & 132 & $18.1 \%$ & 166 & $26.3 \%$ & 358 \\
\hline Const. and Real & $22.2 \%$ & 9 & $57.1 \%$ & 7 & $37.5 \%$ & 16 & $37.5 \%$ & 32 \\
Estate & $22.1 \%$ & 77 & $54.0 \%$ & 124 & $31.0 \%$ & 274 & $35.6 \%$ & 475 \\
\hline Retail & $0.0 \%$ & 1 & $25.0 \%$ & 4 & $5.9 \%$ & 17 & $9.1 \%$ & 22 \\
\hline Financial & $21.1 \%$ & 508 & $39.4 \%$ & 908 & $20.2 \%$ & 1553 & $26.2 \%$ & 2969 \\
\hline \multicolumn{1}{|c|}{ Total } & & & & & & & \\
\hline \hline
\end{tabular}

Source: Prepared by authors

\subsection{Determinants of TPA.}

$H_{1}$ : Which variables determinate the accuracy of target prices, controlling by research departments fixed effects?.

Tables 2 and 3 show the regressions equations using the probit model (marginal effects) and OLS, respectively, also we used all the variables explained above (section "Methodology"). Controlling by research division, the dummies by period show that there is a lower probability of success in the TP. A negative relationship is observed for POST and POMPT in 2008 and this is consistent with the early tables, which show that 2008 was the worst performing year. This also occurs for the other two variables POPT and EPO with opposite signs, since they measure the degree of error of the TP. There are no significant fixed effects by sector for the variables POST, POMP and $\mathrm{EPO}$, showing that the predictive capacity is independent of the firm's sector, only the POPT variables shows evidence for the sector variables. The ranking variable is only significant for the $\mathrm{POPT}$ and $\mathrm{EPO}$ variables, showing an important learning in the issuing of the TP over time, the sign is negative and statistically significant, so we can say in spite of TPA is low, there is a process of performance improvement as the years pass. The "Expected return" variable has a small effect, close to zero, and contrary to what was thought a priori, a very high TP (or low, depending on the kind of recommendation) does not systematically affect the success of the forecast.

In addition, the research department fixed effect does not play an important role as a determinant of the target price accuracy, that is because the repressor associated with market variable do not change too much when research department fixed effects are incorporated.

The variables associated with the previous ranking of the research department are only" significant for the POPT and EPO variables, the coefficient is consistent with idea that higher previous ranking implies lower forecast error. This result is very important for the following hypothesis because we will show evidence that investors might identify the research department with better performance and generate higher abnormal returns. 
Lastly, market variables like $M R$, Momentum $_{i}$ and the volatility of the stock "Sigma" are significant and generally have the expected sign, positive. These variables indicate that the success of the recommendations and of TPs is determined more by the movement of the market and the particular stock, rather than by the capacity of the research divisions, this is because the analyst forecast are related to the fundamentals of the firms, but they are not capable to predict market timing of the market in twelve months in advance. Depending on the kind of recommendation, it is to be expected that the TP will be reached when the market (trend) also moves in the direction of the analyst's forecast. The speed with which the stock reaches the TP is directly linked to the cumulative return of the stock in the forecast horizon "Momentum".

Table 2. Regressions Probit

\begin{tabular}{|c|c|c|c|c|}
\hline \multicolumn{5}{|c|}{ Probit Model : Marginal Effects } \\
\hline \multicolumn{5}{|c|}{$\begin{array}{l}\text { This table shows the determinant of target Price accuracy. The first variable has a Yes if the } \\
\text { regression is controlling for "Research Department". }\end{array}$} \\
\hline & \multicolumn{2}{|c|}{ POST } & \multicolumn{2}{|c|}{ POMPT } \\
\hline Controlling for Research Division & Yes & No & Yes & No \\
\hline 20061 First Semester & $-0.0991^{\star \star \star \star}$ & & $-0.1227^{\star \star \star}$ & \\
\hline 20062 Second Semester. & $0.1074^{7 \ldots-}$ & & $0.1715^{\star \star \star \star}$ & \\
\hline 20071 First Semester & $-0.0706^{*}$ & & 0.0310 & \\
\hline 20072 Second Semester & -0.0013 & & -0.0533 & \\
\hline 20081 First Semester & $-0.1486^{\star \star \star \hbar-}$ & & $-0.1638^{\star \star \pi \star}$ & \\
\hline 20082 Second Semester & $-0.1828^{\star \pi *}$ & & $-0.2980^{\star \pi * \pi}$ & \\
\hline 20091 First Semester & -0.0570 & & $-0.0941^{\star}$ & \\
\hline 20101 First Semester. & 0.0163 & & -0.0255 & \\
\hline Utilities & -0.0060 & & -0.1198 & \\
\hline Other & -0.0528 & & -0.1337 & \\
\hline Com \& Tec & 0.0006 & & 0.1957 & \\
\hline Consumption & 0.0544 & & -0.1215 & \\
\hline Commodities & 0.0110 & & -0.0431 & \\
\hline Banking & 0.0158 & & -0.0091 & \\
\hline Construction and Real Estate & $0.4014^{\star}$ & & -0.0846 & \\
\hline Industry & 0.0895 & & 0.0469 & \\
\hline Retail & -0.0376 & & -0.0503 & \\
\hline Expected returo & -0.0000 & 0.0000 & $0.0000^{* \pi *}$ & $0.0000^{* \pi *}$ \\
\hline MR & $0.5119^{\star \star \star}$ & $0.7214^{\star \star \star}$ & $0.9585^{\star \star \star \star-}$ & $1.0963^{\star \star \star}$ \\
\hline Momentum & 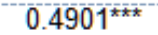 & $0.4687^{\star \star \star \pi}$ & $0.9215^{\star \star \star-}$ & $0.8825^{\star \star \star \pi}$ \\
\hline Sigma & $10.6691^{1 \ldots \pi-}$ & $9.1073^{* \ldots \pi}$ & $15.7375^{\star \pi \star}$ & $12.6101^{\ldots \pi \ldots}$ \\
\hline Hold & $0.1148^{\star \star \pi}$ & $0.1301^{\star \star \star-}$ & $0.2069^{\star \star \star}$ & $0.2209^{\star \star \star \star-}$ \\
\hline Buy & $-0.1170^{\star \star \star \pi-}$ & $-0.0748^{\star \pi \hbar-}$ & $-0.1476^{\star \pi \hbar-}$ & $-0.1037^{\star \star \star \hbar}$ \\
\hline $\log (\mathrm{MKCap})$ & $0.0206^{\star--}$ & $0.0217^{\star \star \star \epsilon-1}$ & -0.0013 & $0.0191^{\star *}$ \\
\hline R POST ${ }^{*}$ Ranking & -0.0038 & $0.0145^{\star \star-}$ & & \\
\hline RPOMPT ${ }^{\star} \mathrm{P}$ Ranking & & & 0.0045 & -0.0048 \\
\hline & & & & \\
\hline Qbservations & 2,650 & 2,650 & 2,643 & 2,650 \\
\hline
\end{tabular}

Note: The Model used is a OLS model since that the depend variable is a continuous variable. Fixed effects by research division, the kind of recommendation, sector and the period that the target Price was issued are controlled with a dummy variable.

*** Significant at the $1 \%$ level, ${ }^{* *}$ Significant at the $5 \%$ level, ${ }^{*}$ Significant at the $10 \%$ level. 
Table 3. Regressions OLS

\begin{tabular}{|c|c|c|c|c|}
\hline \multicolumn{5}{|c|}{ OLS Model } \\
\hline \multicolumn{5}{|c|}{$\begin{array}{l}\text { This table shows the determinant of target Price accuracy. The first variable has a Yes if the } \\
\text { regression is controling for "Research Department". }\end{array}$} \\
\hline & \multicolumn{2}{|c|}{ POPT } & \multicolumn{2}{|c|}{ EPO } \\
\hline Controlling for Research Division & Yes & No & Yes & No \\
\hline 20061 First Semester & $0.1223^{\star \star}$ & & 0.0826 & \\
\hline 20062 Second Semester & 0.0159 & & 0.0415 & \\
\hline 20071 First Semester & $0.0953^{\star^{-}}$ & & 0.0320 & \\
\hline 20072 Second Semester & 0.0640 & & 0.0679 & \\
\hline 20081 First Semester & $0.2385^{\star \star \star \star}$ & & $0.1453^{\star \star}$ & \\
\hline 20082 Second Semester & $0.2633^{\star \star \pi *}$ & & 0.0534 & \\
\hline 20091 First Semester & $0.1142^{\star \star}$ & & 0.0064 & \\
\hline 20101 First Semester & 0.0515 & & 0.0535 & \\
\hline Utilities & $0.1394^{* \star}$ & & 0.0905 & \\
\hline Other & $0.1589^{\star \star \star}$ & & 0.1068 & \\
\hline Com \& Tec & 0.0294 & & 0.0136 & \\
\hline Consumption & $0.1256^{\star *}$ & & 0.0602 & \\
\hline Commodities & $0.1011^{\star}$ & & 0.0662 & \\
\hline Banking & $0.1833^{\approx k}$ & & $0.1936^{\star \star}$ & \\
\hline Construction and Real Estate & $0.1210^{\star \star}$ & & 0.0971 & \\
\hline lndustry & $2.8937^{\star \star \pi \star x}$ & & $3.0041^{\star \pi \ldots}$ & \\
\hline Retail & $0.1267^{\star \pi-}$ & & $0.1249^{*-}$ & \\
\hline Expected return & $-0.0000^{\star \star}$ & $-0.0000^{\star \pi \star}$ & $-0.0000^{\star}$ & 0.0000 \\
\hline MR & -0.0606 & $-0.2422^{\star \star}$ & 0.0906 & -0.0457 \\
\hline Momentum & $-0.7637^{* \ldots \pi}$ & $-0.6946^{\star \star x+}$ & $0.3165^{\star \star x *}$ & $0.3585^{\star \pi \times-}$ \\
\hline Sigma & $-6.9256^{\star}$ & -5.1118 & 1.5006 & 2.0249 \\
\hline Hold & $0.2229^{* \pi k}$ & $0.1687^{\star \star \star \star \pi}$ & $0.3127^{\star \star \star \star \pi}$ & $0.2619^{\star \star \star \pi}$ \\
\hline Buy & $0.4367^{\star \star \pi *}$ & $0.3571^{k \pi \ldots-1}$ & $0.4186^{\star \star \pi-}$ & $0.3448^{* \pi k-1}$ \\
\hline $\log (\mathrm{MKCap})$ & $-0.0461^{\star \star \star \star}$ & $-0.0879^{\star \star \star}$ & $-0.0637^{\star \star \star}$ & $-0.0987^{\star \star \star}$ \\
\hline R POPT ${ }^{\star} \mathrm{D}$ Ranking & $-0.0201^{\star \pi}$ & $-0.0223^{\star \star}$ & & \\
\hline REEPO ${ }^{*}$ Ranking & & & $-0.0258^{\star \pi \ldots-}$ & $-0.0297^{* x *}$ \\
\hline Constante & $0.6329^{\star \star}$ & $1.8926^{\star \star}$ & $1.0883^{\star \star \star}$ & $2.0089^{\star \star \star \star}$ \\
\hline Qbservations & 2,650 & 2,650 & 2,650 & 2,650 \\
\hline R-squared & 0.2929 & 0.1471 & 0.2413 & 0.0674 \\
\hline
\end{tabular}

Note: The Model used is a OLS model since that the depend variable is a continuous variable. Fixed effects by research division, the kind of recommendation, sector and the period that the target Price was issued are controlled with a dummy variable. level.

*** Significant at the $1 \%$ level, ${ }^{* *}$ Significant at the $5 \%$ level, ${ }^{*}$ Significant at the $10 \%$

\subsection{Cumulative Abnormal Returns (CAR): Year and surprise.}

$\mathrm{H}_{2}$ : Do we find abnormal returns when a new target price is issued?. $H_{3}$ : Do we find abnormal returns when a new target price issued is above (below) of target price consensus?

Table 4 shows that the cumulative abnormal returns on the announcement day of a TP are consistently significant for the buy recommendation. The highest average CAR was in 2008 with $1.2 \%$ (buy). The sell recommendation also had cumulative abnormal returns significant at a $90 \%$ confidence level in 2009, reaching -1.1\%. For years 2007 and 2010, the CARs are significant at a $90 \%$ confidence level in the case of sell recommendation. Finally, 
the cumulative abnormal returns of a hold recommendation approach zero or negative (and statistically significant in the year 2010). In general, depending on kind of recommendation, the announcement of a new TP generates cumulative abnormal returns negative or positive and significant at least at $90 \%$ of confidence level.

Table 4. Cumulative Abnormal Return by Year

\begin{tabular}{|c|c|c|c|c|}
\hline Year & Recommendation & CAR & Test-t & $\mathrm{N}$ \\
\hline \multirow{3}{*}{2005} & Sell & $-0.3 \%$ & -0.98 & 46 \\
\hline & Hold & $-0.1 \%$ & -0.60 & 97 \\
\hline & Buy & $0.7 \%$ & 4.33 & 166 \\
\hline \multirow{3}{*}{2006} & Sell & $-0.2 \%$ & -1.19 & 125 \\
\hline & Hold & $-0.1 \%$ & -0.49 & 241 \\
\hline & Buy & $0.5 \%$ & 4.96 & 448 \\
\hline \multirow{3}{*}{2007} & Sell & $-0.2 \%$ & -1.76 & 220 \\
\hline & Hold & $0.0 \%$ & 0.05 & 256 \\
\hline & Buy & $0.6 \%$ & 5.54 & 460 \\
\hline \multirow{3}{*}{2008} & Sell & $-1.0 \%$ & -1.04 & 18 \\
\hline & Hold & $-0.3 \%$ & -0.89 & 89 \\
\hline & Buy & $1.2 \%$ & 5.27 & 166 \\
\hline \multirow{3}{*}{2009} & Sell & $-1.1 \%$ & -1.89 & 44 \\
\hline & Hold & $0.1 \%$ & 0.41 & 111 \\
\hline & Buy & $0.6 \%$ & 2.69 & 171 \\
\hline \multirow{3}{*}{2010} & Sell & $-0.5 \%$ & -1.74 & 61 \\
\hline & Hold & $-0.3 \%$ & -2.30 & 192 \\
\hline & Buy & $0.8 \%$ & 6.23 & 252 \\
\hline
\end{tabular}

If T-test is greater than 2.57 the CAR is significant at the $1 \%$ level, If T-test is greater than 1.96 the CAR is significant at the $5 \%$ level, If T-test is greater than 1.64 the CAR is significant at the $10 \%$

Table 5 shows the cumulative returns classified by the Surprise ${ }^{3}$ variable. The surprise is when a TP issued is greater (lower) than the market consensus, which it is the average of all current TPs for a certain company. Consistently over the years, positive Surprise produces positive cumulative abnormal returns, while negative surprise does not produce statistically significant CAR. When the surprise is positive there is between a $0.3 \%$ and $0.7 \%$ cumulative abnormal return in the event period. This result is very important due to we find evidence of abnormal returns when there is a positive surprise in the market.

\footnotetext{
3 When the new target price is greater than the market consensus, it is called a positive surprise. Meanwhile, when the target price is lower than the market consensus, there is a negative surprise
} 
Table 5. Cumulative Abnormal Return by Surprise

\begin{tabular}{|c|c|c|c|c|}
\hline \multicolumn{5}{|c|}{$\begin{array}{l}\text { When the new target price is greater than the market consensus } \\
\text { the surprise is positive, it is called a positive surprise }(+) \text {. } \\
\text { Meanwhile, when the target price is lower than the market } \\
\text { consensus, there is a negative surprise }(-) \text {. Finally, when the } \\
\text { target price is equal to the market consensus there is no surprise } \\
(0) \text {. }\end{array}$} \\
\hline Year & Surprise & CAR & Test-t & $\mathrm{N}$ \\
\hline \multirow{3}{*}{2005} & - & $0.1 \%$ & 0.59 & 110 \\
\hline & 0 & $0.3 \%$ & 1.18 & 84 \\
\hline & + & $0.5 \%$ & 2.30 & 115 \\
\hline \multirow{3}{*}{2006} & - & $0.1 \%$ & 1.06 & 313 \\
\hline & 0 & $0.2 \%$ & 0.72 & 65 \\
\hline & + & $0.3 \%$ & 2.67 & 436 \\
\hline \multirow{3}{*}{2007} & - & $0.0 \%$ & 0.31 & 197 \\
\hline & 0 & $0.5 \%$ & 1.16 & 28 \\
\hline & + & $0.3 \%$ & 3.31 & 711 \\
\hline \multirow{3}{*}{2008} & - & $0.2 \%$ & 0.57 & 90 \\
\hline & 0 & $2.7 \%$ & 1.29 & 4 \\
\hline & + & $0.7 \%$ & 3.30 & 179 \\
\hline \multirow{3}{*}{2009} & - & $0.0 \%$ & 0.12 & 93 \\
\hline & 0 & $0.6 \%$ & 0.41 & 2 \\
\hline & + & $0.3 \%$ & 1.35 & 231 \\
\hline \multirow{3}{*}{2010} & - & $0.2 \%$ & 0.67 & 40 \\
\hline & 0 & $0.0 \%$ & 0.00 & 0 \\
\hline & + & $0.2 \%$ & 2.18 & 465 \\
\hline
\end{tabular}

If T-test is greater than 2.57 the CAR is significant at the $1 \%$ level, If T-test is greater than 1.96 the CAR is significant at the $5 \%$ level, If T-test is greater than 1.64 the CAR is significant at the $10 \%$ level.

\subsection{Cumulative Abnormal Returns (CAR): Ranking.}

$H_{4}$ : Are abnormal returns greater when a top ranked research department (in terms of accuracy) issues a new target price?

Table 6 does not show a clear and direct relationship between the CAR by kind of recommendation and the brokerage firm ranking in the previous year, grouped by quintiles. ${ }^{4}$ However, over the years the abnormal returns gain statistical significance and magnitude. The buy recommendation continues to have positive cumulative abnormal returns, but there is no clear pattern showing

\footnotetext{
4 In Table 6 all the measures are ordered so that the table reads from the worst ranked quintile to the highest ranked. For the years 2007 and 2008 we do not report the results. However, conclusions are the same for years 2009 and 2010.
} 
that the cumulative abnormal returns are found in the highest ranked brokerage firms (except in the year 2010 where in the POST measure we can see that the abnormal returns are higher in the Q4 and Q5 compared with Q1 and Q2), which is consistent with the earlier regressions. The various metrics for precision level highlight the lack of a clear relationship.

Table 6. Cumulative Abnormal Return by Ranking : Year 2009-2010

\begin{tabular}{|c|c|c|c|c|c|c|c|c|c|c|c|c|c|c|}
\hline & & \multicolumn{13}{|c|}{ 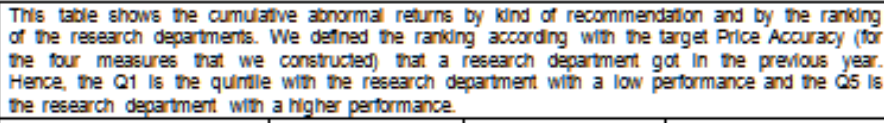 } \\
\hline & & \multicolumn{4}{|c|}{ POST } & \multicolumn{3}{|c|}{ POMP } & \multicolumn{3}{|c|}{ POPT } & \multicolumn{3}{|c|}{ EPO } \\
\hline \multicolumn{2}{|c|}{ Yeax } & $Q$ & CAR & Ies-t & $\mathrm{N}$ & CAR & Ies-t & $\mathrm{N}$ & CAR & Ies-t & $\mathrm{N}$ & CAR & Ies-t & $\mathrm{N}$ \\
\hline \multirow{15}{*}{2009} & \multirow{5}{*}{ Sell } & Q1 & $-1.7 \%$ & -1.4 & 3 & $-1.7 \%$ & -1.4 & 3 & - & - & - & - & - & - \\
\hline & & $\mathrm{C2}_{2}$ & $-2.4 \%$ & -1.7 & 9 & $-24 \%$ & -1.4 & 5 & $-2.1 \%$ & -1.4 & 7 & $-20 \%$ & -1.7 & 10 \\
\hline & & $Q 3$ & $-10 \%$ & -1.1 & 24 & $-0.8 \%$ & -09 & 22 & $-1.1 \%$ & -1.3 & 24 & $-10 \%$ & -1.1 & 20 \\
\hline & & $\mathrm{Q}$ & - & - & - & $-1.5 \%$ & -1.1 & 8 & $-0.8 \%$ & -0.4 & 6 & $-1.8 \%$ & -10 & 5 \\
\hline & & Q5 & $-1.2 \%$ & -0.6 & 3 & $-1.2 \%$ & -0.6 & 3 & $-1.3 \%$ & -0.9 & 3 & $0.4 \%$ & 0.3 & 4 \\
\hline & \multirow{5}{*}{ Hold } & Q1. & $1.4 \%$ & 13 & 7 & $1.4 \%$ & 13 & 7 & $0.4 \%$ & 0.3 & 4 & $0.4 \%$ & 0.3 & 4 \\
\hline & & $Q 2$ & $0.0 \%$ & -0.1 & 28 & $-0.1 \%$ & -0.1 & 15 & $-0.4 \%$ & -0.7 & 33 & $-0.6 \%$ & -12 & 35 \\
\hline & & 03 & $0.3 \%$ & 0.8 & 47 & $0.4 \%$ & 0.8 & 45 & $0.2 \%$ & 0.5 & 41 & $0.6 \%$ & 1.1 & 32 \\
\hline & & Q4 & $-0.1 \%$ & -01 & 15 & $-0.1 \%$ & -01 & 30 & $0.3 \%$ & 0.4 & 25 & $-0.1 \%$ & -02 & 27 \\
\hline & & Q5 & $-1.2 \%$ & -1.2 & 9 & $-1.2 \%$ & -1.2 & 9 & $2.7 \%$ & 20 & 3 & $23 \%$ & 23 & 7 \\
\hline & \multirow{5}{*}{ Bux. } & Q1 & $0.1 \%$ & 0.1 & 9 & $0.1 \%$ & 0.1 & 9 & $-0.4 \%$ & -0.4 & 5 & $0.1 \%$ & 0.1 & 6 \\
\hline & & $Q 2$ & $10 \%$ & 22 & 47 & $1.3 \%$ & 27 & 42 & $09 \%$ & 24 & 69 & $10 \%$ & 26 & 68 \\
\hline & & Q3 & $0.5 \%$ & 1.4 & 75 & $0.5 \%$ & 13 & 69 & $0.4 \%$ & 12 & 60 & $0.3 \%$ & 09 & 58 \\
\hline & & Q4 & $0.6 \%$ & 12 & 26 & $0.4 \%$ & 0.8 & 37 & $0.4 \%$ & 0.7 & 32 & $03 \%$ & 0.5 & 30 \\
\hline & & Q5 & $0.2 \%$ & 0.2 & 14 & $0.2 \%$ & 0.2 & 14 & $1.1 \%$ & 1.0 & 5 & $1.3 \%$ & 1.7 & 9 \\
\hline \multirow{15}{*}{2010} & \multirow{5}{*}{ Sall } & Q1. & $-10 \%$ & -28 & 35 & $-0.8 \%$ & -19 & 26 & $-1.5 \%$ & -20 & 8 & $-0.4 \%$ & -0.4 & 4 \\
\hline & & 02 & $0.2 \%$ & 0.3 & 7 & $0.7 \%$ & 0.7 & 5 & $-0.6 \%$ & -1.5 & 34 & $0.3 \%$ & 0.6 & 15 \\
\hline & & Q3 & $0.8 \%$ & 0.7 & 3 & $-0.5 \%$ & -1.1 & 21 & $1.3 \%$ & 10 & 3 & $0.8 \%$ & 0.7 & 3 \\
\hline & & Q4 & $0.3 \%$ & 0.4 & 7 & $-0.1 \%$ & -01 & 5 & $00 \%$ & 0.1 & 10 & $07 \%$ & 10 & 8 \\
\hline & & $\mathrm{C5}$ & $0.4 \%$ & 0.5 & 7 & - & - & - & $-0.4 \%$ & -0.4 & 4 & $-1.3 \%$ & -3.2 & 29 \\
\hline & \multirow{5}{*}{ Hold } & Q1 & $00 \%$ & 02 & 49 & $-0.2 \%$ & -0.6 & 31 & $-1.3 \%$ & -30 & 22 & $-09 \%$ & -21 & 28 \\
\hline & & $Q 2$ & $-0.6 \%$ & -21 & 42 & $-0.6 \%$ & -22 & 67 & $-0.1 \%$ & -0.5 & 70 & $0.0 \%$ & 0.1 & 25 \\
\hline & & Q3 & $-0.4 \%$ & -09 & 23 & $-0.1 \%$ & -03 & 43 & $-0.1 \%$ & -03 & 34 & $-0.5 \%$ & -12 & 26 \\
\hline & & $\mathrm{Q}$ & $-0.4 \%$ & -1.4 & 52 & $-0.5 \%$ & -12 & 22 & $-0.2 \%$ & -0.6 & 25 & $-0.6 \%$ & -20 & 45 \\
\hline & & Q5 & $-19 \%$ & -1.7 & 4 & $-0.2 \%$ & -0.3 & 7 & $-09 \%$ & -1.8 & 19 & $0.0 \%$ & 0.1 & 45 \\
\hline & \multirow{5}{*}{ Buk } & Q1 & $0.6 \%$ & 29 & 25 & $0.5 \%$ & 21 & 65 & $1.1 \%$ & 37 & 38 & $0.8 \%$ & 24 & 39 \\
\hline & & $Q 2$ & $0.7 \%$ & 24 & 51 & $09 \%$ & 42 & 91 & $0.5 \%$ & 24 & 97 & $1.4 \%$ & 4.4 & 39 \\
\hline & & Q3 & $-0.1 \%$ & -02 & 21 & $1.4 \%$ & 52 & 61 & $1.6 \%$ & 51 & 46 & $-0.4 \%$ & -09 & 28 \\
\hline & & Q4 & $1.1 \%$ & 42 & 62 & $-0.3 \%$ & -0.7 & 16 & $0.8 \%$ & 25 & 41 & $1.0 \%$ & 3.6 & 55 \\
\hline & & Q5 & $1.5 \%$ & 3.5 & 23 & $-0.9 \%$ & -1.5 & 9 & $-0.5 \%$ & -1.2 & 20 & $0.7 \%$ & 32 & 20 \\
\hline
\end{tabular}

If T-test is greater than 2.57 the CAR is significant at the $1 \%$ level, If T-test is greater than 1.96 the CAR is significant at the $5 \%$ level, If T-test is greater than 1.64 the CAR is significant at the $10 \%$ level 


\section{Conclusions.}

The target price accuracy appears to be low across research divisions, although in the last years there is an improvement in the success of the target price. On the other hand, we showed empirical evidence that the target price generates abnormal returns in the announcement day. Those results suggest that target prices have an important informational power despite of the low target price accuracy. Therefore, there is a big query related with the real contribution of target prices and analyst recommendation, because they are not the only products of the research departments. For instance, earnings forecasts are very useful information for the investor and also there is empirical evidence in the literature that shows a good performance of analysts related with earning forecasts and how through the TP and analyst recommendation the investors can create portfolios with higher returns. Also, investors could find contingent information about companies in the financial reports.

Hence, we believe that the forecast horizon of the target price is the big issue for the research divisions, because they are not capable (nobody) to predict the timing of the market and how fast it goes up or down. That is the key in the discussion; giving a forecast horizon to achieve the price that the analyst believes is very complicated, Why it is important the horizon time?, Is it good to give to the target price a deadline? At this point we are not saying that target prices do not provide useful information to the market, rather the conclusion that we can make, is related with timing of the market and the issue of the forecast horizon, which is an unexplored field yet.

The relationship between precision level and abnormal returns on the target price announcement day is not clear; the ranking of the brokerage firms would not systematically affect the existence of abnormal returns on the announcement day. The precision level is determined by market variables and specific characteristics of the stock rather than by the predictive capacity of analysts. However, the precision of target prices has increased over time, which could be a clear sign that over time knowledge has increased which is related to the creation of research divisions in brokerage firms as an essential part of the business.

Abnormal returns are primarily focused on the buy recommendation when there is a new target price. However, the clearest and most powerful effect is when this new target price generates a market surprise, which according to the EMH produces an adjustment in the price to reflect that new information. Also, the results do not permit establishing a clear relationship between the ranking of research departments and abnormal returns. 


\section{References}

Asquith, P., Mikhail, M. and Au, A. (2005). Information Contents of Equity Analyst Reports, Journal of Financial Economics, 75(2), pp. 245-282.

Bilinski, P., Lyssimachou, D. and Walker, M. (2012). Target Price Accuracy: International Evidence. The Accounting Review, 88(3) pp. 825-851

Bonini, S., Zanetti, L., Bianchini, R. and Salvi, A. (2010). Target Price Accuracy in Equity Research, Journal of Business Finance and Accounting, 37(9-10), pp. 1177-1217.

Braber B., Lehavy, R., McNichols, M. and Trueman B. (2001). Can Investors Profit from the Prophets? Security Analyst Recommendations and Stock Returns, The Journal of Finance, 56(2), pp. 531-563.

Bradsahw, M. (2004). How Do Analyst Use Their Earnings Forecast in Generating Stock Recommendations?, The Accounting Review, 79(1), pp. 25-50.

Bradsahw, M. (2012). Analyst Target Price Optimism around the World, Working Paper, Boston College.

Bradshaw, M. and Brown, L. (2007). Do Sell-Side Analyst Exhibit Differential Target Price Forecasting Ability?, working paper, Harvard Business School and Georgia State University, USA, 1 March.

Bradsahw, M., Huang A. and Tan H. (2012). Analyst Target Prices and Forecast Accuracy around the World, working paper Boston College and University of Waterloo, April 12

Brav, A., Lehavy, R. (2003). An Empirical Analysis' Target Price: Short Term Informativeness and Long-term Dynamics, The Journal of Finance, 58(5), pp. 19331968.

Feldman, R., Livnat, J., Zhang, Y. (2012). Analysts' Earnings Forecast, Recommendation and Target Price Revisions, Journal Portfolio Management, 38(2), pp.120-132.

Frankel, R.; Kothari, S. P. and Weber, J. Determinants of the Informativeness of Analyst Research, Journal of Accounting and Economics, 41(1-2), pp. 29-54.

Hall, J., Tacon, P. (2010). Forecast Accuracy and Stock Recommendations, Journal of Contemporary Accounting and Economics, 6(1), pp. 18-33.

Huanga, J., Mujtaba, G. and Sankaraguruswamyc, S. (2009). The Value of Combining the Information Content of Analyst Recommendations and Target Prices, Journal of Financial Markets, 12(4), pp.754-777.

Jegadeesh, N. and Kim, W. (2006). Value of Analyst Recommendations: International evidence, The Journal of Financial Markets, 9(3), pp. 274-309.

Loh, R. and Stulz R (2011). When are Analyst Recommendation Changes Influential. Review of Financial Studies, 24(2) pp. 593-627.

MacKinlay, A. (1997). Event Estudies in Economics and Finance, Journal of Economic Literature, 1(1), pp. 13-39.

Moshirian, F., Ng, D. and Wu, E. (2009). The Value of Stock Analysts' Recommendations: Evidence from Emerging Markets, International Review of Financial Analysis, 18(1-2), pp. $74-83$.

Womack, K. (1996. Do Brokerage Analysts' Recommendation have Investment Value?. American Finance Association 51(1), pp. 137-167. 